\title{
APUNTES Y COMENTARIOS A LA LEY DE CONTRATACIONES DEL ESTADO
}

\section{(DECRETO LEGISLATIVO 1017)}

\author{
Alexcangana Mouna Dimitajkyich \\ Nhogade per la Chvirsidat de Line

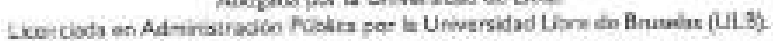

\section{SUMARIO:}

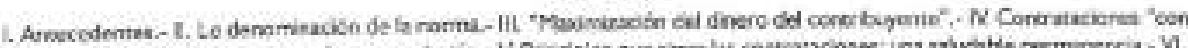

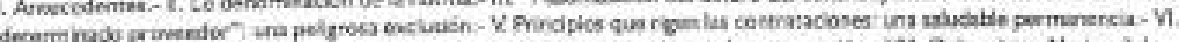

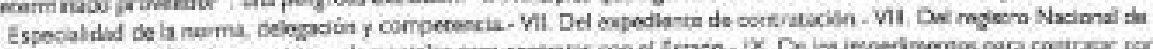

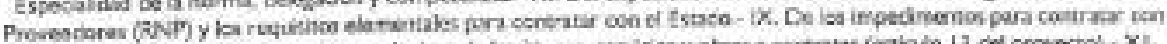

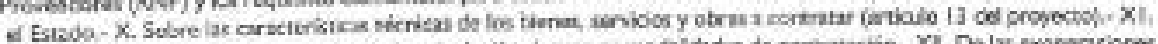

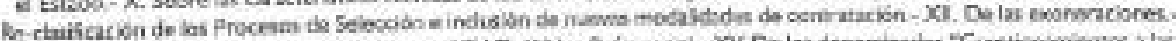

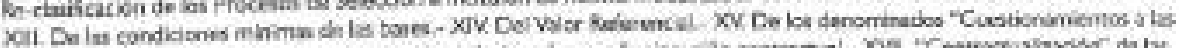

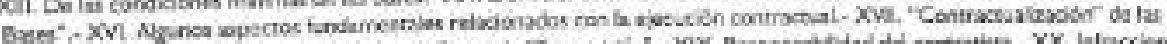

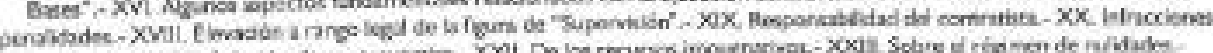

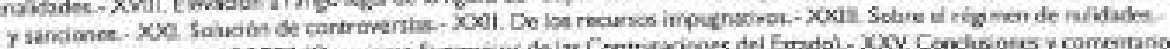

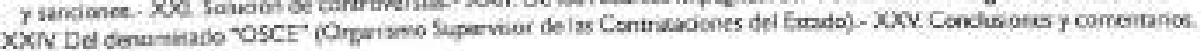

\section{ANTECEDENTES}

Mediante Oficio No. 157-2007-PR, de facha 7 de agosto de 2007, el Ejecurtvo remitio al Congreso el proyecto de la Ley' que, suatituyendo el régimen de rango legal compilado por ef Decreto Supremo No. 083-2004-PCM (Texto Único Ordenado-TUO- de la Ley de Contrataciones y Adquisiciones del Estado, aprobada incialmente por Ley 26850), tione por objeto regular los procesos a través do los cuales el Estado elige a sua co-contratantes, asi camo también ha consecuente ejecución de los contratos que se deriven de dicha selección. La intención inicial y central de quienes desarrollaron dicho projecto, no reposabs en otra cosa que en la nocesana renoración yio actualización del régimen instaurade por la Ley 26850, Ley de Contrataciones y Adquisiciones del Estado:

Meses después, con fecha 20 de diciembre de 2007, se publica en el Diario Oficial Fl Poruano la Ley 29157, bautizada con el exterso nomive de "Ley que deicga en ef foder Ejecutho la Facultad de Legislar sabre dfversos moterias pelacianados con íc implementoción dof acuerdo de framaión Conerciaf Peru - Estadas Unidos y call el aboyo a la campetitividad econámica poro su oprovechiomiento", Ley sutoritativa' mediante la cual sa delege al Podor Elecsitivo facultades para que éste, en un plazo de ciento octienta $(180)$ dias calendario, legisle sobre las materias ospecifeadias en la misma normas. con la finalidad de facticar la implementacián del Acuerdo de Promoción Comencial Perú-EEUU y su prococalo de enmienda, y el apoya a la compecitividad economica. Entre catas materias se encuentra la rrejora del marco regulatorio, fortalecimiento irstitucional y simplificación ad́ministrativa y modernización del Estado.

Propecto be tivy 140202007.FE

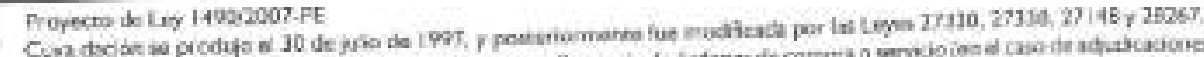

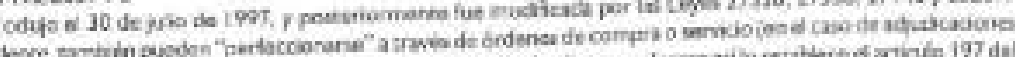

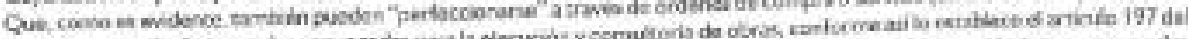

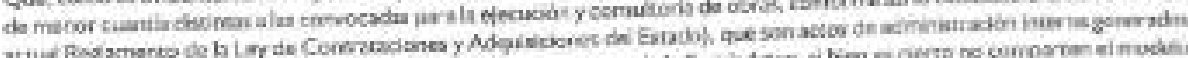

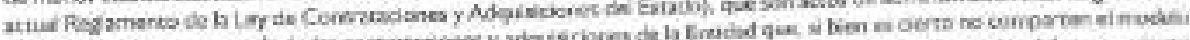

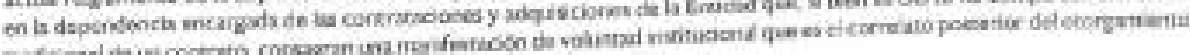

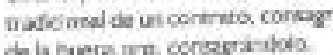

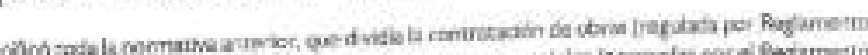
Wom Whico de Lizzocoses Coutrace da Qs

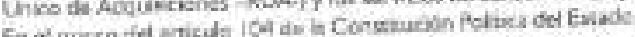


Corno consecuencia de ello, y dentro del plazo conferido por la precitada Ley Autoritativa, el 4 de junio de 2008 se publicó en El Peruano el Decreto Legishativo 1017, Ley de Contranciones del Estado. De igual modo, en la misma fecha, se publica el Decreto Legislativo I018, norma que crea la por muchos esperada "Central de Compras Püblicas - Perù Compras".

Visto este panorama inicial, el presente articulo tiene como finalidad esencial comentar los aspectos de la mieva normativa que, a nuestro parecer, revisten mayor importancia, realizando un analisis comparativo entre esta y la normatividad aùr vigente', asi como también complementando nuestros comentarios al nuevo régimen a aprobarse con los aportes doctrinarios que pudieran ser esclarecedores, coherentes con la realidad peruara y con la diversa problemática que tiene que enfrentar la Adrrinistración a la hera de seleccionar a les particulares con quienes requiere contratar para agenciarse de bienes, servicios, o para la ejecución de aquellas obras que, dentro del marco del cumplimiento de sus fines, requiere la población.

\section{il. LA DENOMINACIÓN DE LA NORMA}

A diferencia del régimen que, en lo esencial, fue aprobado mediante Ley 26850, Ley de Contrataciones y Adquisiciones del Éstado $(1997)^{7}-y$ que inclusive hasta la fecha regula los Ineamientos básicos que deben observar las Entidades del Sector Público en los proceson de contratación de bienes, servieios u obras que éstas requieran-, la norma se cuida de incurrir en la confusiōn terminológica contenida en el régimen actual. En efecto, équé diferencia a una adquisición de una cantratación? o iqué las hace figuras idénticas? iPorque? i) quien adquiero lo hace goneralmente en mèrito a un contrato", i) quien contrata no siempre "adquiere", pups se adquiere blenes, pero resulta claro que "adquirir" no es ul término más adecuado para el caso do los servicios, in en general, en lo que atahe a las obras, la propiedad de "lo construido", se "adquiere" porque estas, en virsud de lo prescrito por el articulo 938 del Código Civil, se adhieren al suelo perteneciente a un propietario determinado, pero aquf lo que importa no es establecer el régimen de propiedad de obras construidas por cuenta del Estado, sino establecer el régimen de contratación en sí de la persona natural o juridica que ojecutari las mismas, con lo cual la palabra "adquisición" termina siendo, para efectos prácticos, irrelevarte, Sea como sea, una técnica legislativa adecuada implica claridad en el texto de la ley, sobre todo cuando se trata de disposiciones que no solo se utilizan en el quehacer cotidiano del abogado, sino también, del ingeniero o del adininistrador (logistico), como es el caso de la normativa en materia de contrataciones del Estado. Por tanto, consideramos un scierto del projecto la supresión de la palabra "adquisiciones".

\section{ii. "MAXIMIZACIÓN DEL DINERO DEL CONTRIBUYENTE"}

Laprimera parte del articulo 2 del Proyecto señala que "(...) El objetivo de esta Ley es establecer las normas orientadas a masimizar el valor del dinero del contribuyente en las contrataciones para proveerse de bienes, servicios u obras por parte de las Entidades del Estado (....).

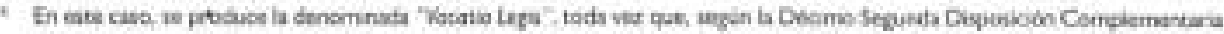

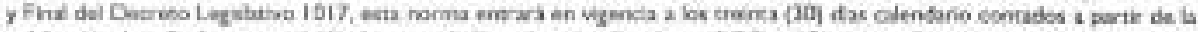

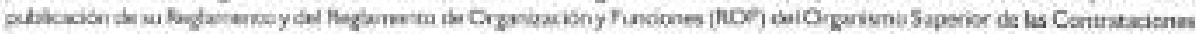

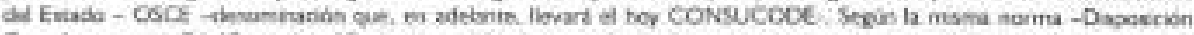

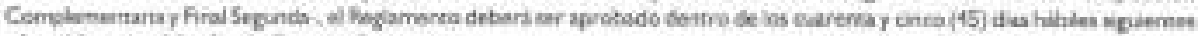

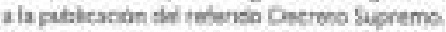

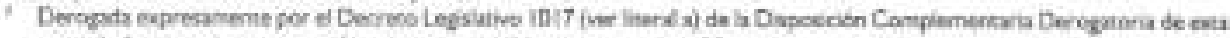

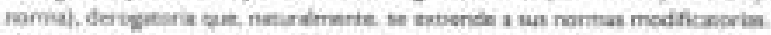

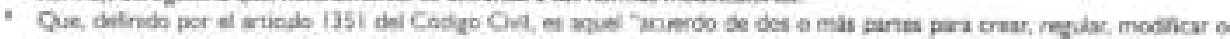

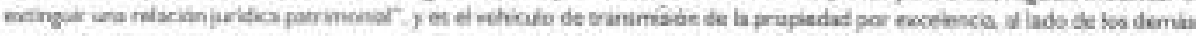

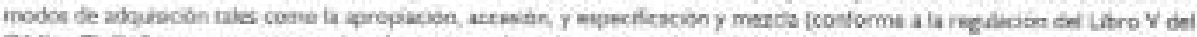

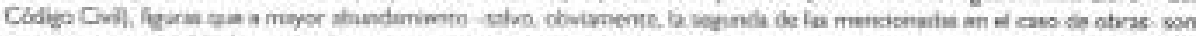

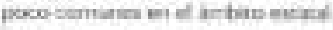

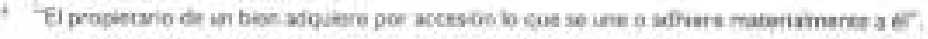


¿Cómo hacer encajar este mandato dentro de una porspectiva puramente juridica, más allis de lo que se considera como "corveniente"? Recordemos que: L. El direro del contriburyente ingresa a las arcas del Estado, en grar medida, por la via de los impuestos, que, corro sabemos. son tributos no vinculados. "Z, En segundo lugar, "el dicero dal contribuyente" no és el úrico elemento que constituye las finarzas públicas dol Estado." 3. Finalmente, el término an s', aparantemente, no tendria mayor coherencia cen la narurzleza del imterís público y los fines estatsles, seria mís armónico con la reslidad empresarial. Ahora bien, mís alla de de estas consideraciones téenico|uridicus, pareciera que la conveniencia de incluir este túrmono provendría de un (a nuestro encender y en este caso justificado), ánimo de pragnnatismo político. En efecto, a nuescro juicio, oventualmente, aquil la intención de quien alaboró el proyecto fue de alguna marnera irtroducir frases qua refuercen una insyor conxiencia tributaria, asi como tambièn, per el lado del funcionario públice encargado de las concrataciones y adquisiciones del Estade, relorzar uns convicción fracia el tuen usa del dinero estatal, actitud que siempre denotarí apego al correcto ejercicio de la función pública.

\section{CONTRATACIONES "CON DETERMINADO PROVEEDOR": UNA PELIGROSA EXCLUSIÓN}

Se ha incluido el literal " $\mathrm{k}$ " al numeral 3.3, del articule 3 del preyecto, que excluye del àmbițo de apicación de la norma a aquellas contratsciones qus deben real izurse con determirado proveedor, por mandato expreso de loy o de autoridad jurisdiccional.

A nuestro paracer, si el Legislativo decide mentener este texto, el Reglatiento que en su oportunidad se emita, deberia regular los alcances de io indicado antoriormerte, y lo deberá hacer de modo estricto, para que la soccepción no se convierta en regla, y, sobra todo, para que la inclusión de esta pasiblídad, paradójicamenté, no se comiorts en una peligosa exclusión.

\section{PRINCIPIOS QUE RIGEN LAS CONTRATACIONES: UNA SALUDABLE PERMANENCIA}

El propecto prewio a la norma que finalmente se pualicó (vale decir, el remit do a Congraso mediante Oficio No. 157-2007-PR') dejaba prácticamente intactos ${ }^{4}$ los principios que deben regir las contrataciones estatales. A diferencia de ello, el Decreto Legislariwo 1017 martiene los ocho (8) principios vigentes, agregando sin periuicio de ello les siguientes:

Principio de Promoción de! Desarroilo Humano: Que, segün el legislador delegado, supone

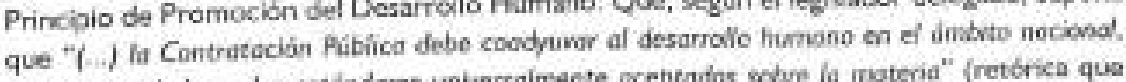
de conformidad con los estaindares untersaimente oceptados sobve ia insteria" (retorica qua podris sugerir cierta "inhibición" del legislador, quien se cuida de uthizar el ténnino "Derechos Humanos" -técnicamente el que resultaria más apropiado- el mismo quo, en diertos sectores. puode resultar politicamente incorrecto).

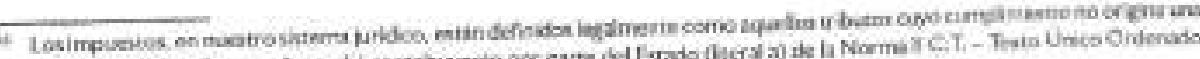

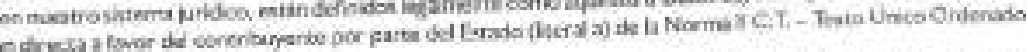

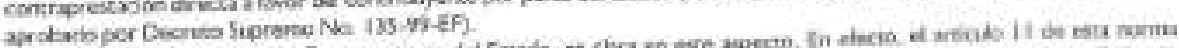

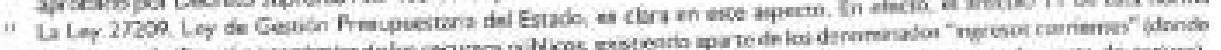

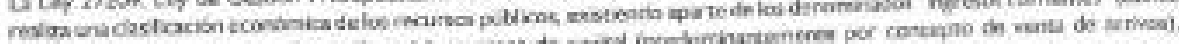

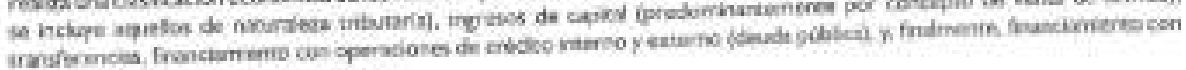

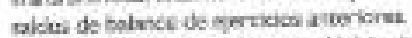

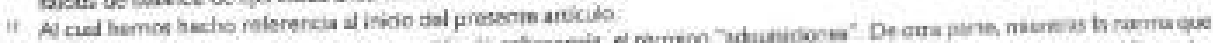

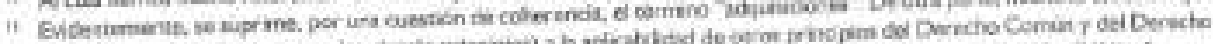

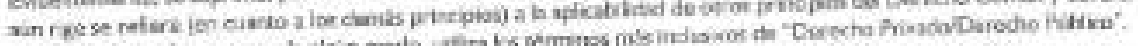

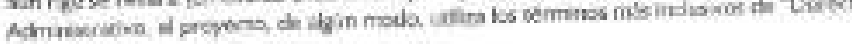


- Principio de Rezonabilidad: Según el cual "en todos fos procrsos de selección al objeto de fos contratos debe ser razaneble. en términos cuostitovins y cuentotimos, para satisfacer el interés. público y el resultodo esperodo". Consideramcs acertada la inclusión de esce principlo, pese a su imprecisa redacción (ya que la fase contractual es posterior al desarrollo de los proceses de selección) y a la redundancia en que se incurre al final de la frase, pues a nuestro parecer el resultado esperado de toda compra estatal no es otro que la plasmación da todos los principios y firalidades consagrados por la norma, lo cual en buena cuenca sarisface ol interés público.

Principio de Publeidad: Segùn el cual "las convecetorias de los proceses de selecciän y las actos que se dicten como cansecuencle" deberán ser publicados $y$ difundidos adecuada y suficientemente a fin de garantizar la concurrencia de los potenciales postores. Hay que precisar, en este punto, gue este principio se extiende z todo el proceso de selección a, incluso, a la suscripción de los contratos, y tiene en el Sistema Electrónico de Adquisiciones y Contrataciones del Estado (SEACE) una certera herramienta hacia su materialización.

- Principio de Equidad: De conformidad con este principio, "los prestociones y derechos de las portes deberón guoordor una ruzonable relacián de equivalencia y proporcianalidad, sin perjuicio de las focintodes que corresponden ar tatado en la gestión del interts gentrol". So trats, pues, de una "equidad" que, en un primer momento, aparece como "relativizada", garantizándose una preeminencia del interés general que enervaria la equivalencia de prestaciones que en principio caracteriza a todo contrato. Sin embargo, en el fondo, tingararalia del interḱs puiblice no hav equidad posible"t, y no es más que el Estado el primer llamado a garentizarlo.

- Principio de Sestenibildad Ambiental: Se indica que "(...) en todo contratoción se oplicardn cnteries pard gorontizar lo sastenibuidad ambiental, procurando entar impactos ambientales negatiras en cancardancia con les normas de lo muteria". Este principio podria resultar plenamente aplicable en los casos de compra de combustible o contratación de obras.

También se efectúan ciertas adiciones yó modificaciones a los principios ya existentes, que conviene comentar:

Se cambia la denominación del acrual "Principio de Libre Competencia" por la "Libre concurrencia y competenxia" (cuando los términos competencia y concurrencia, en la práctica. vienen a ser lo mismo). ${ }^{13}$

- Se sustituye, en lo que atañe al "Principio de Eficiencia", la confusa frase "bienes, servicios - ejocución de obras que se adqueran o contraten" por una fórmula más precisa: "las contrataciones que realicen las Entidades deben efectuarse bajo las mejores condiciones", asi como también se agrega que debe hacerse "el mejor uso de los recunos materiales y humanos disponibles", debiendo las contrataciones observar "criterios de celeridad, economia y eficacia", siendo este un pertinente diseño de ete principio.

- En lo correspondiente al Principio de Tato justo e lgualitario, se quita la ítima frase ("salvo las excepciones de ley"), lo cuad saludamos, ya que la esencia de este principio no deberia contemplar excepción algura, pues supondria un verdadero contrasentido.

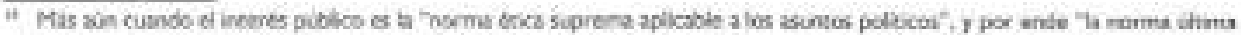

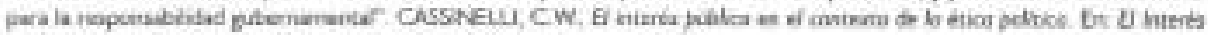

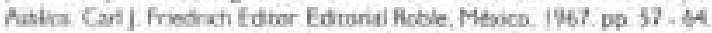

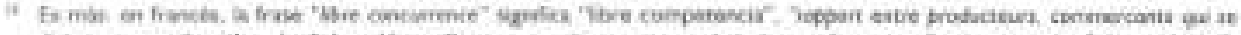

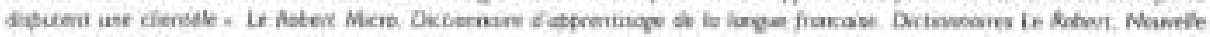
Edtuan Mark Issa 
Debemos recordar ademas que, el hecho de qua una norma dedique un exterso articulo a regular el tema de los principios, reviste una vital importancia por cuarto los mismos informan todo el cuerpo normativo (legal y por ende, el reglamentario, que se debe a aquel) que regula este tema. Corto asi lo sefhala Marcial Rubio ${ }^{t h}$, tales principios (en atención a su esencia) tienen un carbicter axiológico, pero en tote caso, al lado de esta naturzleza, corvive un ineludible caracter técnico, nutriendo fa estructura, el moda de operacibn y el contenido de este nígmen tan particular.

Además de mantener este aspecto positivo dé cuerpo legal comentado, la norma, acertadamente, ubicz la finalidad, la razón de ser de estos principios, en el articulo que regula al objeto da la norma (articula 2). En tal sentido, su función es más que crucial, retirando a los principios do un espaclo que podria perobirse como meramente lírico fo interpretarse como tal por quienes, imbuidos de un espicitu extremadumente pragmático, les arribuyen - a nuestro juicio erróneamente - inutilidad), para articularlos con dicho objeto noc mativo, confiriéndeles la importancia prictica çue les corresponde, a ser los carales centrales para plasmar aquello que la normat busca. La respuesta al trillado ipara qué sirven? es. pues, más que obvia.

\section{ESPECIALIDAD DE LA NORMA, DELEGACIÓN Y COMPETENCIA}

La norma publikada echa mano constartemente de la dicotomla (para alyunos caduca, pero para ncsotros aù viable pars efectos básicarnente didactiocs) Derecho PúblicojDerocto Frinado. Esta se repite en el artikulo 5, que regula la especialidad de la norma y delogracón. En efecto, segùn la nurma bejo correntario, la Ley y el Regiamento "prevalecen sobre las nomas de cerecho puiblico ${ }^{2 a}$ y sobre. acuelas de derocho privado que le seen aplicables. Al respecto, es importante preosar que las primeras (fundamentalmente la Ley 27444, Ley del Procodimiento Administranvo General) se aplican de manera suplotoria a ta etapa que va desde la convocatoria hasta el ccorgamiento de ha buena pro, mientras que hs segundas (fundamentalmente el Codigo Covil) son de aplicación (siempre supletoria), a ta etapa de ejecución contractual. En este punto, consideramos importante recordar que, dentro de las discusiones sobre la naciraleza juridica del régimen de contrataciones del Estado (donde junistas como Manuel de la Puente y Lavalle - perspoctva civilsta- sostienen que se tara de Contratos Privodos", frente a la posición bastarte difundida en el mecio, en el sersido de que se trata de Contratos Administrathos -perspectia que podriamos llamaar "adminstrativista" -$)^{20}$, compartimos la posición de Santofimio, acisocriterio "( -..)

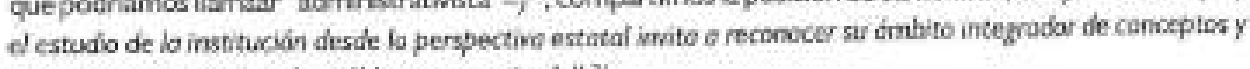
prixcipies tonto de derecho pitalios conno privado" 21

Con respocto a la delegación, la norma agrega una serie de situaciones de indeleqabilidad de la competencia para las contrataciones estatales. Cabe precisar que tal competencia le corresponde.

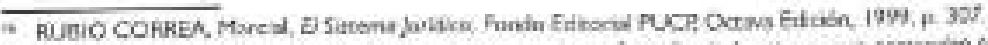

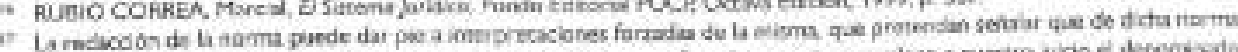

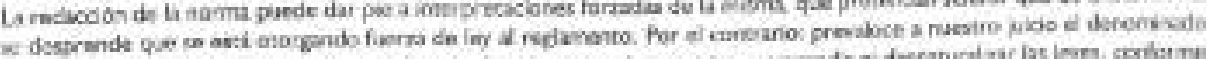

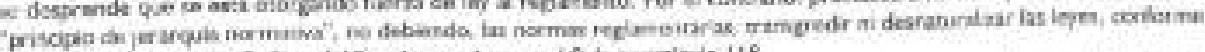

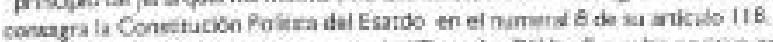

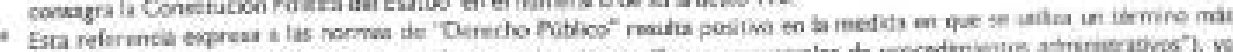

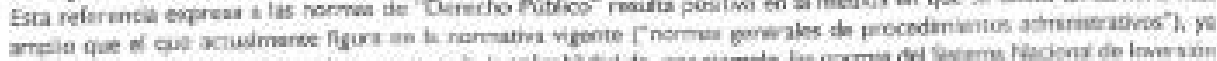

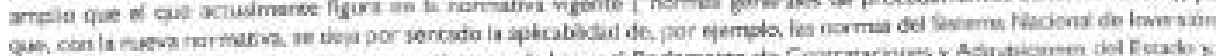

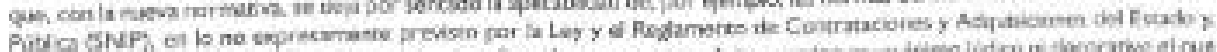

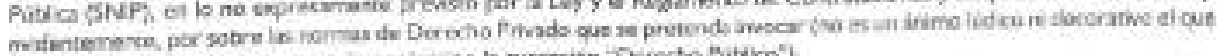

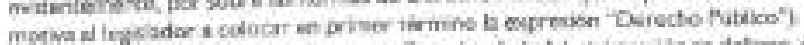

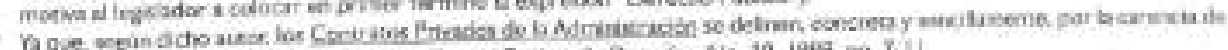

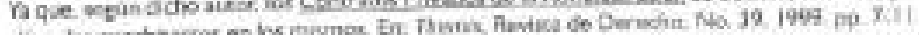

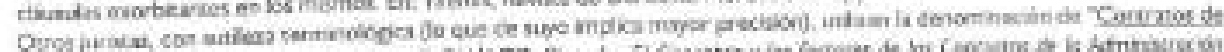

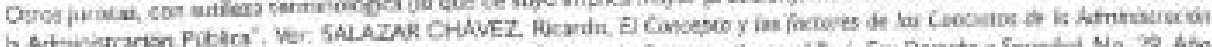

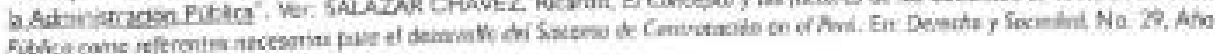
xvil disembre 2007 . pp $55-62$

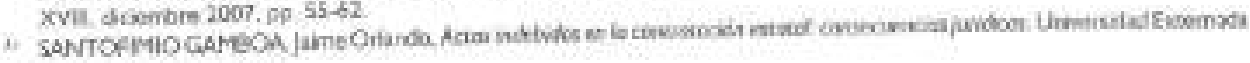
de Cobinhta (Sequrars) 
de por si, al Titular de la Entidad." Asi, éste Último podrád delegar cualquier aspocta relacionado con dicha competencia, siempre y cuando medie una resolución, y quo, basicamente, no se trate de las siguierces situaciones, considenadas cruciales por quien propone el proyecto, a saber a. aprobación de exoneraciones, b. declanción de rulidad de oficio, c. resolución de apelaciones y d. autorización do adionales.

Elo no quita que, an aplicación del principio administrativo de desconcentrsción de funciones ${ }^{3}$, existan órganos que se encazguen de la programación, preparación, ejecución y supervisión de los procesos de contratación hasta su culminación. Este aspecto se encuentra regulado en el artículo 6 del proyecto, que, consideramos, debería agregar que toda esta división funcional no dobe preschindir de la autoridad ( $y$ responsabilicad) del Titular del Pliego.

Lo que nos parece saludable es tacbl gación, plasmada en el segundo párrafo del precitado articulo 6, de que los funcionarica y servidores que se encarguen de las contrataciones, acredisen estar capacitados on la matona, dejindole al roglamento la tarea de normar estos aspectos, en cujo caso, sugerimos que la capacitación pueds ser tóbrica o pristica, y que se consagre (esto siempre en el texto lega) que sobre estas personas no hayan recaido sontenciss judiciales determinando responsabilidad panal.

\section{DEL EXPEDIENTE DE CONTRATACIÓN}

La norma que todavia rigo las contrataciones estatales, le dedica a la ejecución de obras públicas, an su artículo 6, el siguiente párrafo, qua, deszfortunadamente, ha sido eliminado por la norma baso análisis:

"Fare el caso de ejecución de abros, la Entidad debend contar además, previa a la cambeatario dd procese de selecciún carrespondente, can el Expediente Técnico, el mismo que debe cumpir con loa requisitos esteblecidas en el Reglarrenta, debiendo la Entidod cautelar ses odecuado formuloción can el fin de asegurar su celidod técrico y reducir al minimo lo necesidod de su reformulación por erfores o deficiencias técnicos que repercuton en ef proceso de ejeciucián de obres" 24

En lo que comúnmente la normativa denomina "el caso de obras", la alta complejidad tócnica inherente a la ejecución de las mismas hace necesario que el legislador plantee fórmulas de regulación detallada, con el propósito de uniformizar al rógimen, de proporcionar reglas claras y concretas respecto de un tema que, en la príctica, reviste complicados onigmas $y$ dilemas en el seno de las diversas entidades que, para cumplir con sus fines inherentes. deben ejecutarlas, para si (por ejemplo, sedes administrativas) ${ }^{\text {as }}$ o para beneficio directo de la población (colegios, hospitales, carreteras). Un buen intento de sistematizar este tema lo constituye el hecho de que el actual raglamento consagra un capitulo entere a la ejecución de obras. Sin embargo, la calidad de la regulación que aún existe en la nermativa vigente, solo genera desorden e informalidad en la ejocución de obras, y una enorme casuistiça que a su vez es causa de demoras innecesarias. En este contexto, se desaprovecha una oportunidad

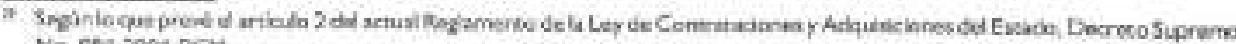
No. 6eA.3004.PCH.

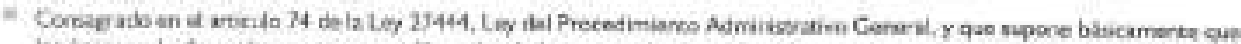

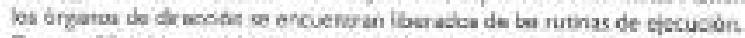

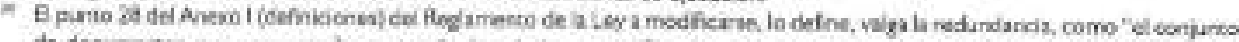

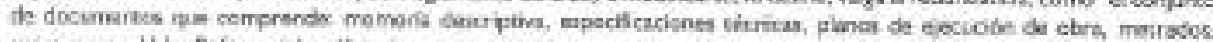

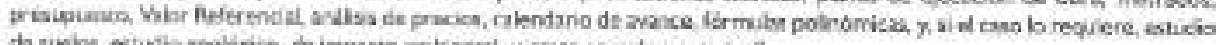

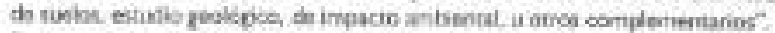

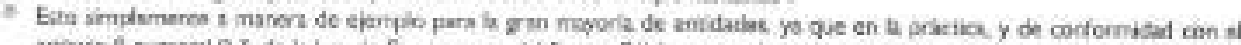

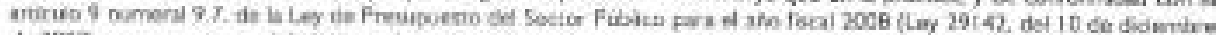

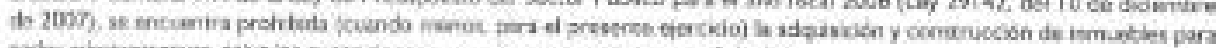

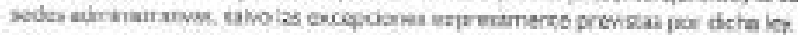


de dotar a la normativa de disposiciones más solidas, en materia de obras, a contcacorriente do lo que realmante se necesita ragular.

\section{DEL REGISTRO NACIONAL DE PROYEEDORES (RNP) Y DE LOS REQUISITOS ELEMENTALES PARA CONTRATAR CON EL ESTADO}

En esta parte de la norma, encontramos como novedad positiva la linclusión de una adecuada terminolog/a. En efecto, mientras que el articulo 8 de la norma que aín nge se refiere únicamante a los postores, aquí se incluye los términos "participante, postor y/o contratista", lo cual no deja absolutamente ninguna duda (que de ple a interpretaciones contrarias al interés público) acerca de la abligación de estar inscrito en registros en todas las etapas que implica la contratación estatal, ${ }^{\text {It }}$

Criticames que, sin embargo, se incluys la frase "impedido, sarioorado ri inhabiltrado" ya que, como es obvio, la inhabilitación es la especie y la sanción el género. La inhubilitación es, en efecto, en el ámbito de la contratacißón estatal, la sanción por excelencia, pero también existan sanciores económicas aplicables. En tódo caso, el proyocto, para cvitar redundanxias, debió limitarse a decir que para ser postor, participante yío contratista, se requiere (aparte de estar inscriko en el RNP). no estar impedido ni irhabilitado para contratar con el Estado.

\section{DE LOS IMPEDIMENTOS PARA CONTRATAR CON EL ESTADO}

Sobre les impedimentos para contratar con el Estado (regulades en el articulo 10 del projecto), que en esancia constiouyen ina regulación fundamental para la lucha contra la corrupóón, no podemos dejar de mencionar lo siguiente:

Con buena tècrica legislativa el articula se inicia con la frase "cualquiora sea el régimen legal de contratación aplicable", creemos que con el afán de evitar que se transgreda la nocma a traves de figuras contractuales que escondan la participación, como vendaderos contratistas, de aquellos que se encuentren impedidos de serlo.

- Sin embergo, no se suprime (o adapta a la realidad), como seria necesario, la inadeciada mención al "órgano colegiado de los organismos constitucianales autónemos" (iculi es?). En este punto, resulta vilido poner el ejemplo de la Defensoria del Puoblo, organismo constitucionalmonte autónomo (segùn articulo 16 ! de la Constitución Politica del Estado) que carece de "órgano colegiado".

El liveral e) -que impide participar a quienes hayan teaido intervención directa en la determinación de las características técnicas, por una cuessión de orden y de congruenciadebió preciaar como obvia excepción a la regla en el plasmada al donominado "Concurso Olerta", modalidad en la cual el contratista de una obra es también el cncargado de elaborar el Expediente Tecrico.

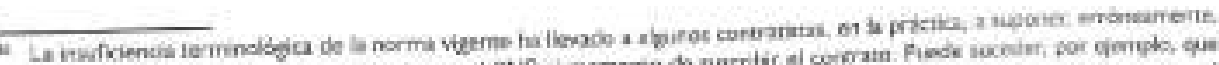

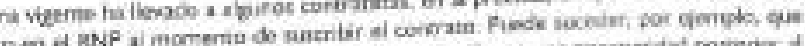

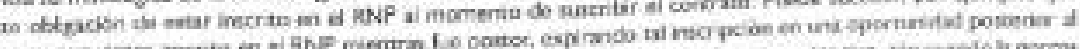

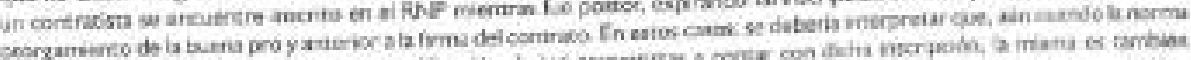

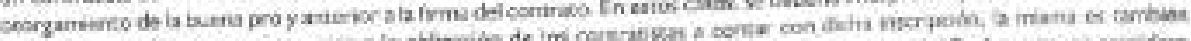

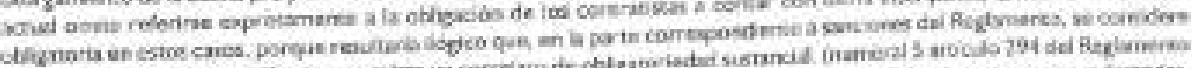

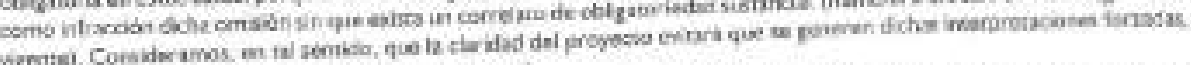

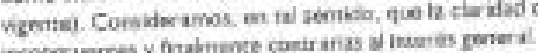

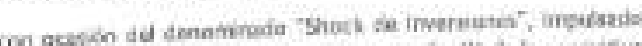

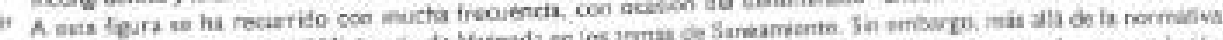

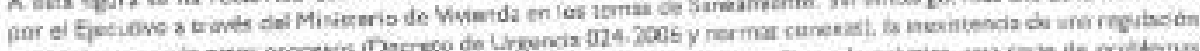

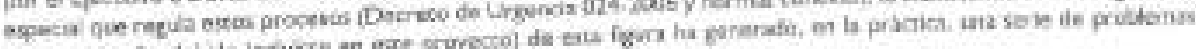

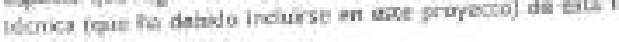




\section{SOBRE LAS CARACTERISTICAS TECNICAS DE LOS BIENES, SERVICIOS Y OBRAS A CONTRATAR (ARTICULO I3 DEL PROYECTO)}

Reformulando la reguàión que se encuentra aún vigente, la nueva norma coloca expresamente como punto de partida y referencin fundamental pare todo requerimiento al Plan Anual de Contrataciones (definido por el articulo 8 del propio proyecto como aquel documento que, bàsicamente, debe prever todas las contrataciones de bienes, servicios y obras que se requerirán durante ol año fiscal).

- De otra parte, se eìmina, con acierto ly en salvaguarda de los Principios de Eficiencia. Libre Competencia y de Moralidad en la Contrataciones públicas), la posibilidad de que las indagaclones sean aleatorias. Se incluye, en este sentido, la obligación de que dicha evaluacíx́n garantice una pluralidad de proveedores en el mercado para la convocatoria respectiva. La norma tedavia vigente, solo circurscribe la obligación de estudies tóenicos previes a los casos de Licitaciones y Concursos Püblicos, olvidándose de que el grueso de las contrataciones. pasa por procesos de Adjudicación do Menor Cuantia *

- Se consagra un texto más amplio y elaborado que regule las características técricas en el delicado "caso de cbras". Asi, se agregan términos como "disponibilidad fisica del terreno", b que, evidentemente, no alude a una mera disponibilidad, sino más bien a la posibilidad concreta de tomar posesión dol mismo, aunquo a nusstro juicio se ha debido considerar también la posibilidad juridico-legal de que la Entidad tenga el derecho de propiedad del terreno y que éste se encuentre debidamente saneado. También se inserta la obligación de que se cuente con un Expediente Téenieo aprobado (olvidándose, eso si, hacer la salvedad para el caso del denominado "Concurso Oferta", sobre cuya complejidad nos hemos reforido en lineas precedentes), y se consagra que se debe reducir al minimo la necesidad de reformular el mismo a causa de errores o deficiencias técnicas que repercutan en el proceso de ajecución de obras, un hecho recurrente que genera sobrecostos a las entidades, amen de contravenir con claridad los Principios de Eficiencia y Economia en la Contratación Publica. Al margen de osto, la norma, en general, deberia beindar una regulación especifica del caso de "consultoria de obras", figura que se encuentra a medio camino entre los servicios y las obras, y que en la actualldad carece de un régimen rermativo concrete que le de un cauce uniforme" a la elaboración de los estudios técricos que influyen de modo directo en la calidad de la obra a ejecutarse, a fin de minimizar, por ojomplo, la posibilidad de adicionales

\section{RE-CLASIFICACIÓN DE LOS PROCESOS DE SELECCIÓN E INCLUSIÓN DE NUEVAS MODALIDADES DE CONTRATACION}

Se introduce, en el articuio 15 de la norma, una denominación coherente con el panorama actual de las contrataciones estarales. Asi, se utiliza el término "mecanismos de selección", que engloba l.a los procesos de selección en si (licitación pública, concurso público, adjudicación directa y adjudicación de menor cuantia), 2.a la modalidad de selección denominada "subasta imersa", y 3, a las compras corporativas que se realizan, de acuerdo con el segundo y tercer parrrafo del ahudido articulo, por Convenis Marca. Se agregan, adembs, cuestiones propias del e

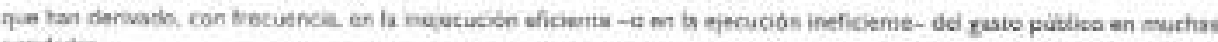
Griedades.

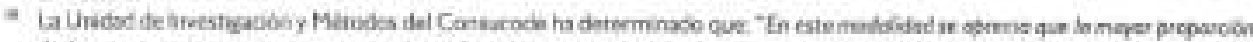

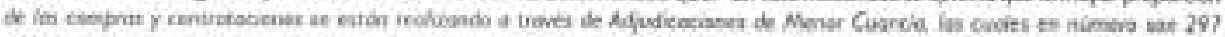

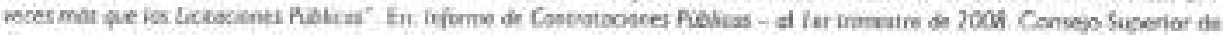

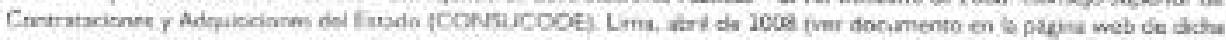

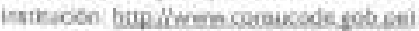

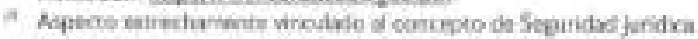


- government" (panorama que no se apreciaba cuando se gestó la estructura medular de la norma vegente, en épocas de la Ley No, 26850, en que no teniamos la gran incidencia actual de Internet), como el conocido portal del Sistema Electrónico de Adquisiciones y Contratariones del Estado (SEACE) que, seguin es plantea, servirá de media obligatorio para efectuar las adjudicaciones de menor cuantis (articulo 19).

\section{DE LAS EXONERACIONES}

La norma (er su articulo 20 y siguientes) incloye algunas novedades respecto de las exeneraciones de procesos de selección. Rasaltamos la siguiante:

- Se elimina la exoneración a aquellas contrataciones de servicios públicos sujetos a tarifas ünicas."

- Se reformula el tenor do lo que se regula actualmente en el liceral a) del articulo 20 dol Texto Único Ordenado (TUO) de la Ley de Contraraciones y Adquisiciones del Estado, aprobado por Decreto Supremo No 083-2004-PCM (exaneraciones para centratar entre eatidades del Scetor Público). En este caso, se sustituye fa vaga frase de ( (., ) de acuardo a los criterios de economia que establezca el Reglamento", por una oportuna precisión: "(...) siempre que en razón de costos de oportunidad rasultan mís eficientes y tócnicamente viables para satisfacer la necesidad y no se contravenga lo señalado en el articulo 60 de la Censtitución Politica". Es conveniente, en tal sentido, ligar este asunto al Principio de Subsidiariedat consagrado por la Constitución Pelitica del Estado en el precitado articulo 60 , scgün el cual solo autorizado por loy expresa, el Estado puede realizar subsidiar iamente actividad empresarial, directa o indirecta, por razén de alto interćs público o de manifiesta conveniencia nacional. En buena cuenta, se debe cumplir con las requisitos contenidos an el relerido articulo de la Carta Magna.

En rebaciśn con los bienes o servicios que no admiten sustitutos, se actara a nivel legal ta confusión instaurada por el Reglamento" ${ }^{\text {" }}$ (que preciza, en é segundo pirrafo de su a ticula 144, que se considera que existe proveedor único cuando se ha establocido la exclusividad del proveedor por racones técricas)", al introducir en el literal e) del articulo 20 del propecto, un texto bastante más daro y concreto al respecto.

Se agrega un parr afo que deja al Reglamento ta tarea de establecer las formaìdades, condiciones y requisitos complementarios para ceda cosonersción. Siendo asi, canfiamos en que el nuevo Reglamento, fie limites que salvaguanden el interés público y la transparencia, lo cual de ninguin modo debe suponer dejar de lado el concepto de eficiencla en la gestión pública, qus es justamente la razón que explica ba existencia de las exoneraciones, las mismas que, por ese elemento de balance enve lo eficaz y lo correcto, que es inherente a tal concopto, no deben perder en ningún momerito su naturaleza excepcional.

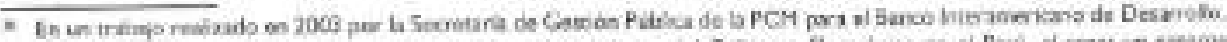

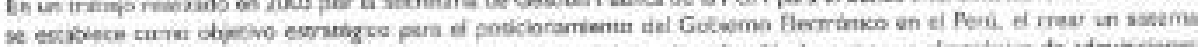

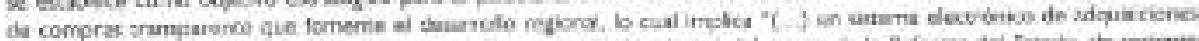

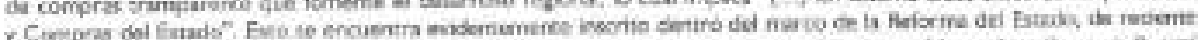

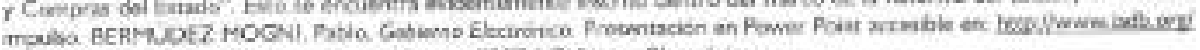

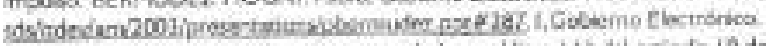

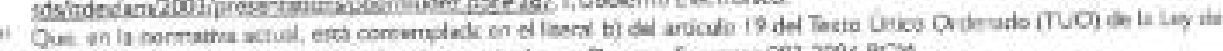

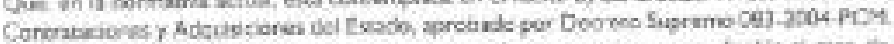

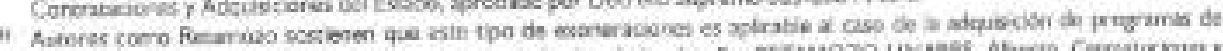

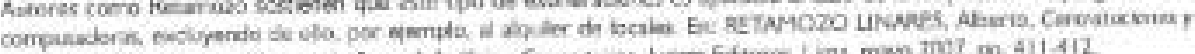

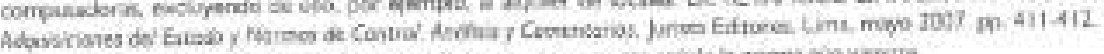

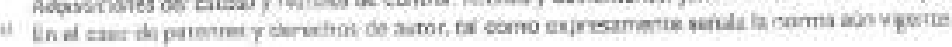




\section{DE LAS CONDICIONES MINIMAS DE LAS BASES}

Al fiar la necesidad de aprobar las boves formaimente", la norma utiliza el término genérico "procesos de selección" y no circurnscribe el rame a has Licitsciones y Concursos Publicos," Asimismo, un alemento que, sin duda alguna, va a reforzar al rol rector del hoy CONSUCODE fque, corno senalaremos más adelante, se denominarí, por mandato de esta norma, OSCE)* lo constituye ha aprobación de bases estandarizadas por pacte de este organiamo, aunque dicha estandarización de bases, sin perder su naruraleza vinculante (para poder lograr unfíormizar el régmen en aras de preservar la seguridad juridica); deberin también ser adaptable para las Entidades, on funciben do cada caso cencreto $y$ de sus proplas nocasidades.

\section{DEL VALOR REFERENCLAL}

Aqui, destacamos el valioso aporte de la nerma, que dota al proceso de delinición dal Valor Referancial de criterios mas objetivos. "De este mode, con el nuevo rëgimen la Encidad, por of contrario, deberiz efectuar estudios y antlisis en el mercado, de los niveles de comercialización, siempre de acuerdo a los parametros que serbin establecidos en el nuevo. Reglamento. Estos parámetros son, conforme vemos, muy distintos a los actuales, que le dan un lugar al elemento aleatorio, lo cual, a nuestro entender, deja ta puerta abierta a la posiblidad de "actos indebidos en la contratación estatal". H"

Asimismo, se incorporan limites mas claros en torno a la antigùedad del Valor Reforencial. Asi, en el denominado "caso de obras", esta no podrá exceder de ses (6) meses a la fecha de la convocatoria, no pudiendo exceder de tres (3) meses tratándose de bienes y servicios, La normativa vigente (articulo 34 del Regiamento), se refiere a una antigiledad no mayor a dos (2) meses, para todos los cases. Siendo asi, nos arrevemos a sostener que la nueva propuesta, en el marco del proceso inflacionario actual, tendria como probable efecto el que se logre mejores precios para ias adquisiciones ostatales.

\section{DE LOS DENOMINADOS "CUESTIONAMIENTOS A LAS BASES"}

En este punto, mis alli de la imprecisión anotada en el parrafo anterior, saludamos que al proyocto defina, con range da lay los conceptos de observaciones y consulkas. En efecto, las primeras son, segün el texto propuesto, "pedidos de aclaracib́n a tas disposiciones de las Bases" $y$ las segundas son mecanismos de cuestionamiento de bases "en lo relativo al incumplimieno de las condiciones minimas o de cunlquior disposición en matena de contracaciones del Estado u otras normas complementarlas o conexis que tergan relación con el proceso de selección".

\section{ALGUNOS ASPECTOS FUNDAMENTALES RELACIONADOS CON LA EJECUCIÓN CONTRACTUAL}

- Seguin la nueva norma, las modificaciones a los contratos se ceñirin a las siriaxiones expressmerite contampladas en el Feglamento. Esta reducciôn en la flexiblidad de los contratos de la sdministración pública, es un ejemplo más de que nos encontramos dentro de un régimen en el cual las disposiciones que atanier al Derecho Público ingresan a ámbitos en los que el Estado (er principio) actúa carno un particular, no pudiendo el Contrato modificarse en basa

\footnotetext{
Es decir, pur at This de la Entadad a por el fanomarin delegado.

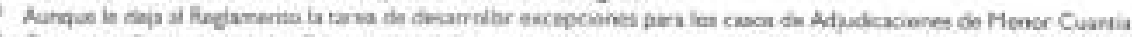

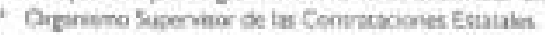

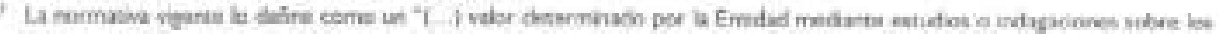

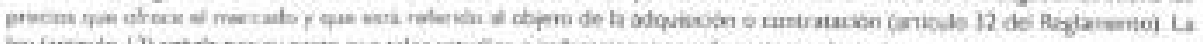

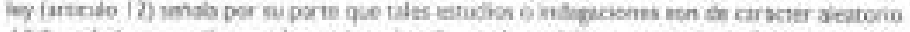

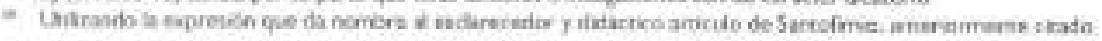


al ejercicio absolutamente libes de la autonomia de la voluntad," Et importante concoruar este punte con el articuio 1355 del Código Civil, el mamo que establece çan cleridad que "(...) la ley. por consideraciones de interés social, públice o écico puede imponer reglas o establecer limitaciones al conterido de los centratos" (el subraydo es nuestro). Segün algunos autores, este articula "doviene en inaplicable" "." par ananto el articulo 62 de la Constitución Politica del Estado dispone que "I libertad de contratar garantiza que las partes puedan pacta" vilidamente segün las nocmas vigentes al tiampo deil contrato" (el subrayado es nuestro). Sin embargo, consideramos que: 1 , al articulo 1355 del Codigo Civil está referide a que las norras " podrian determinar certos cánones ex - ante a fin de preservar el interés público. ${ }^{42}$ Pretender establecer dichos limites de manera ex - post seria contrario al articulo 62 de h1 Constitución - dicho artículo 62 de la Carta Magna ae refiere a las normas vigentes "(...) al tempo del contrato* - 2. En esa medida, los limes a las modificaciones contractiales del Estado, establecidos por el proyecto, nos parecen un gran aporte que el mismo proporciona, porque el sogundo párrafo del articulo 36 (que regula las modilicaciones contractuales bajo la normativa vigonte) es paradoficamente vago y al mismo tiempo está tiznado de arbitraria inflexibilidad: "En este sentido, cuando el reglamento se cxupe de estabiecer dikhoo limites. deberí considerar que ios mismos sean objetivos y raxonables, que respesen los principios er materia de contrataciones y adquisiclones del Estado (establecidos en esta misma Ley), el interes público, pero que al mismo tiempo que no den pie a entrampamiantos de carácter administrativo-intemo que le resten eficiencia a las adquisiciones estatales

- Regresa a nuostro sisterna legal de contrataciones y adquisiciones del Estado la denominada "garantía de seriedad de oferta", a fin de que el Contratista proporcione medios accescrios para asegurar la validez de la misma hasta el otorganiento de la buena pra.

- En relación con la culminación del contrato, la norma añade como requisito para que se produzca elo que se haya efactuado el pago correspondierte. La normativa actual regula este aspecto on el articulo 270 del Reglamento, estableciendo que el contrato culmina con la sola liquidación.

\section{XVII. "CONTRACTUALIZACION" DE LAS PENALIDADES}

El novedoso articulo 48 de la norma comentada, prevé que las persalidades, que teóricamente son sanciones civiles de tipo "predeterminada" según Esccia y por tanto proceden autorniticamentet" serdin establecidas en ef Cantrato. A la fecha, la fórmula polinómiea para la determinación de penalidades se encuentra normada en el articulo 222 del Reglarnento vigente, que usualmente es transcrito en el texto de los diversos contratos suscritos por la Administración bajo el régimen que comentamos. Siendo asi, se establece un margen de libertad mis amplio en este aspecto, en contraposicićn al tema de las modificaciones contractuales, que hemos comentado lineas arriba.

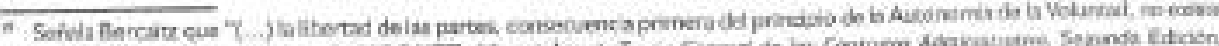

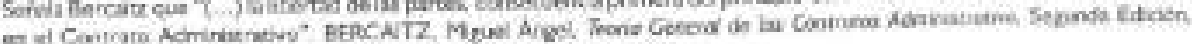

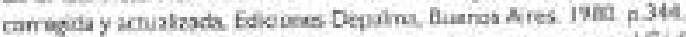

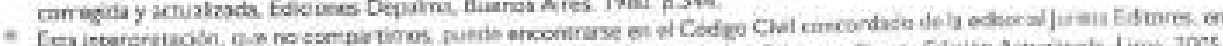

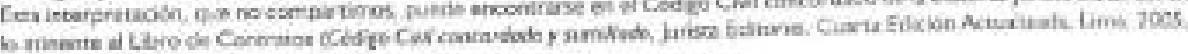
a. $3(4)$

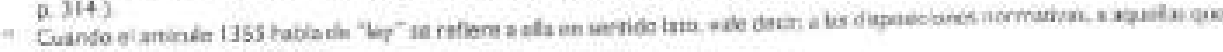

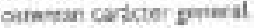

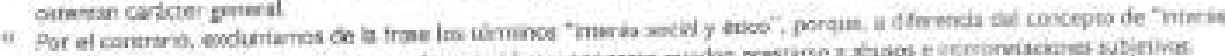

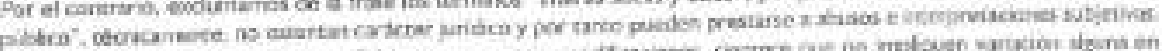

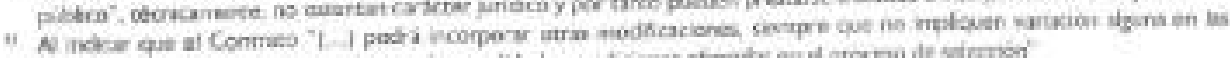

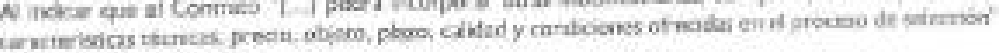

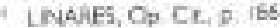




\section{XVIIL.ELEVACIÓN A RANGO LEGAL DE LA FIGURA DE "SUPERVISIÓN"}

La norma, en su articulo 47, olava a rango legal la figura de la Supervisión, configuranda legal y expresamente un "dereche de supervision" para aplicar (por si thisma" o mediante terceros) "los términos contractuales para que el contratista corrija cualquier desajuste respecto del cumplimiento exacto de las obligaciones pactadas"- Asimismo, se advierte al Contratista que la inexistencia en los hechos de una "supervisión" no lo releva de su obligación de cumplir con lo pactado en el contrato.

\section{RESPONSABILIDAD DEL CONTRATISTA}

Resulta acertado que, en la norma, se deje a las Bases la potestad de determinar el plazo máximo de responsabilidad del Contratista. Además, nos parece atinado que se añada (como punto de reforencia indispensable) que el plazo de responsabilidad para los contratistas de obra, se cuente a partir de la recepeión total o parcial de obra, proporcionando asi, para el "easo de obras", un parametro inexistente en la norma legal que aín rige las contrataciones estatsles.

\section{INFRACCIONES Y SANCIONES}

En lo que atahe a las infracciones y sanciones en materia de Contrataciones y Adquisiciones del Estado, la norma vigente, como resulta claro para muchos, transgrede el principio de sipicidad en materia sancionatoria-administrativa, dnsarrollodo por la doctrina y establecido en la Ley 27444. Ley del Procedimionto Adminstrativo General.

En efocto, la potestad sancionatoria-administrativa en nuestro psís está regich, entre otros, por el principia de tipicidad, según el cual solo constituyen conductas sancionables adiministrativamene las infracciones previstas expresamente en normas con rango de ley medianto su tipuficacín como tales, y las disposiciones reglameritarias de desarrollo pueden especificar $\odot$ graduar aquellas dirigidas a identificar las conductas o determinar sanciones sin constiruir muevas conductas sancionables a las previstas legalmente, salvo los casos en que la ley permita tipificar por via reglamentaria farticula 230 numeral 4 de la Ley 27444),

En efecto, sostiene Morón Urbina que ta propia ley puede coctvocar, la concurrencia de la administración para culminar la tarea tipificadora, habilitandole a regular "(...) sólo to minime

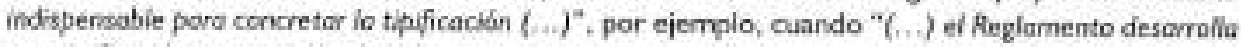
und tipificocián par remisión de la ley (...) consideramos necesaria reiterar ia necesidad que la remisión de la ley af reglamento debo o su vez determinar fo esencial de lo canducto constitutiva del ilicito, pues tampoco sería odmisible per imperfecta una remisión en blance af Foder Ejecutino poro determinar aquello que serd́ suncionsble (... $)^{* 4}$ (el subrayado y la negrila son nuestros). Agrega Morón que el sentido legitima de la frase "salvo que la ley permita tiplicar en via reglamentaria" es que la ley mantenga dentro de su imbito regulatorio lo esencial de la conducta antijuridica."

Contrastando bo indicado con los Decreros Supremos Nos. 083 y 084-2004-PCM, el régimen vigente vulnerz frontalmente los principios del derecho administrativo sancionador. El articulo 52 de la Ley (cuyo Texto Unice Ordenado fue aprobado por la primera de la normas nombradas), seriala en su párrafo pirimero que "El Corsejo Suparior de Contrataciones y Adquisiciones del Estado impondra a les proveedores, participantes, postores, contratistas y entidades, en los casos en que esta Ley o su reglamento serialen, las sanciones siguientes (....) $)^{n}$ la negrila es nuestra - Dentro

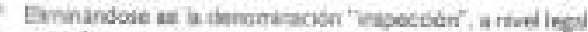

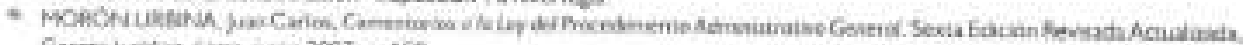

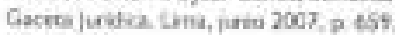

* Tid piss
} 
del orden de ideas hasta aqui seguido si bien es cierto las consecuenclas administrativas terminan siendo señaladas de manera goneral en la propia forma legal, existe una clara remisión en blanco de la Ley al Reglamento, configuraindose de este modo la vulneración a que hemos hecho alusión previamente.

Alortunadatente, el proyecto colocz en el rango que cocresponde a la descripción del grueso de las infracciones administrativas relacionadas con la maneria de Contrataciones y Adquisiciones del Estado, reconociendo asi un principio básiço que se conecta de manera directa con el Estado de Derecho", sin perjuicio de que, en el üttimo inciso del articulo, se indiqua que el Reglarnento tipificara mis infracciones, El Proyecto de Ley 1490/2007-PE (al que hicimos refarencia al inicio del presente articulo) era mas tajante aún, no abriendo la puerta de dicha posibilidad.

\section{SOLUCIÓN DE CONTROVERSIAS}

En el Titulo $V$ de la norma enconeramos que se mantiene la division clara y ardenada entre le que es una conteoversia y una impugnación, Sobre estos dos conceptos, debemos mencionar que, en la contratación estatal, en el primer caso se vata de posiciones encontradas dentro del marco de una relación juridica de co-contratantes que mantienen discrepancias en rebsción con aspectos precisamente contractuales, mientras que el sezundo caso se produce dentro do escenario pre-contractual que caracteriza a los procesos de selección, cuya naturaleza es netarnente "administretiva".

En el caso especifico de las "controversias" (que, de idéntica manera al régimen actial. serán dilueidadas siempre en arbitraje), se aprecia que la norma pre-determina la especialidad de los regimenes juridicos que analizari/utilizard el Thburtal Artitral en el decurso del procnso y. consecuentemente, en la preparación de su decisión final, estableciendo como orden de prelerencia de carácter obligaterio el siguiente. 1) Este Decreto Legishativa y su Reglamento, 2) Las normas de derecho público y 3) las de derecho privado, aún cuando, en el articulo 4) del proyecto ("especialidad de la rorma"), ya esta fijado el orden de prelación de las fuentes çue todos los operadores de esta normarive (incluyendo dentro de este concepto, naturaimente, a los árbitros) deben seguir, aungue., sin perjuicio de esto, probablemente la intención del legislador ha sido la de inhibir de algura manera cierta tendencia "civilsta" que pudiena surgir en sede arbitral.

Ademas, se agrega que, sobre la base del Principio de Transparencia, el ahora denominado "OSCE" debera disponer la utilización de los laudos para el desarrollo de estudios espocializados en mater ia de arbitraje administrativo, lo cual consideramos muy positivo para el desarrollo del arbitraje en el Perú. Imaginamos que, en este caso, será el Reglamento ylo nomas de inferior jerarcuia se encargarán de desarrollar este dispositivo.

\section{DE LOS RECURSOS IMPUGNATIVOS}

Este articulo 53, dedicado a ta regulación de la facultad de contradicción en la etapa pre: contractual (articulo que curiosamente tiene un encabezado en plurai cuando solo habra un recurso: el de apelación) y que es preámbulo irprescindible de toda contratación estatal, consagra ta reciente eliminación de los recurses de revisión, continuando uma tendencia a la simpificación de etapas, come parte del procedimiento especial de cuestionamiento de todo acto impugnable dictado dentro del marco de un proceso de selección, de carbcter, como ya dímos, netamențe adminiùrativo

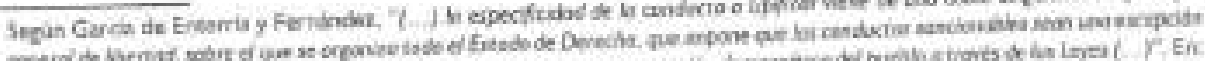

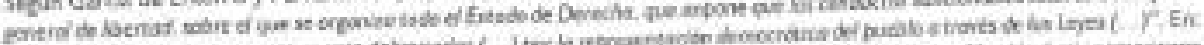

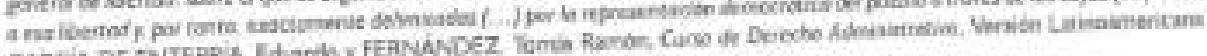

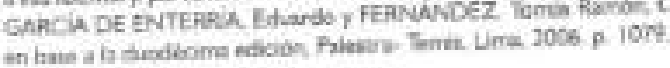


Asimismo, en of segundo parrafo se da a entender que el otorgamiento de la buerna pro es, en esencia, un acto administrativo, al calzar este perfectamente en fa delinición del articulo I de fa Ley 27444 .

Tambièn se hace una distinsiún entre los órganos que conocen y resuebven las apelaciones. Ast, dentró del eseverra planteato en la noma bajo analisis y comentano, el Tribunal se ocupará de las apelaciones suscitadas en los casos de valones roforenclaies que superen las seisciertas $(600)$ Unidades Impositivas Trbutarias (UIT), miensras que a la Entidad (a traves de su titular) le correspondera resolver las apelaciones en fos casos de montos iguales o menores a dicho parametro. En ambos casos, tal como se dedise con facilidad dol primer párrafo del articulo 53 del proyecto, $y$ tal como, de forma caherente y expresa se indica en el tercer párnafo del mismo, el acto administrativo que resuelve una apelación agota la via admiristrativa. El cambio, can respecto a lo plasrado en el Proyocto de Ley 1490/2007-PE (que establecia la skvisión en función del proceso de sciocción del que se tratase), tendria por finaicdad reducir estersiblemente la carga procedimentai del Trbunal de Contratsciones del Estado y, al mismo tiempo, otorgar fscultades resolutivas en materia de Contracaciones y Adquisiciones del Estado a las Enticades.

Finalmente, considerames muy positivo que la Ley consagre la figura de la jurisprudencia de observancia obligatoriz, generach como consecuencia de acuerdos de "Sala Plera" en los que se interpreta de modo expreso y can carketer zeneral ta nomuativa en materia de Contrataciones y Adquisicianes del Estado.

\section{XXII.SOBRE EL REGIMEN DE NULIDADES}

Piegulada en el articulo 56 de ia norma, esta figura, tal como esta dasehada, busca proporcionar una solución juridica adncuada frente a los vicios que se presentan en el proceso de selección, asi camo tambien en les contrasos que se suscribe bajo este ámbito.

La norma vigente, por el contranio, en el caso de nulidad de contratos, reduce la posibilidad de declararba cuando se verifiquen los supuestos conteridos en el articulo 9 de la Ley (es docir, cuando han sido suscritos per quienes estên impedidos para ser postores ylo contratistas), asi como también frente al quebramtamiento del principio de presunción de veracidad (lvego de ser ello comprobado vía fiscalizoión posterior) dejando fuera del firme ámbito de las nulidades a contratos igualmente lesivos al interḱs público pero que estén fuera de dichas caussles.

En cincto, se incorpora la posibilidad de que la Entidad anule de ofics los Contrates por una sorie de caussles expresas que van más allá del escueto o insuficiente texto de la norma que aùn nos rige, en lo que atane al régimen de nulidades. Asti, en el projecto se describe como causales las siguientes:

a) Por haberse suscrito en contravención del articulo 10 de la Ley (se mantiene la nulidad de los contratos suscritos por quien tiene impedirnentios).

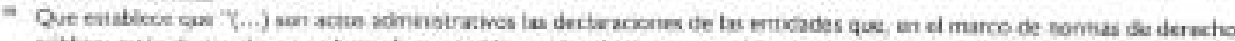

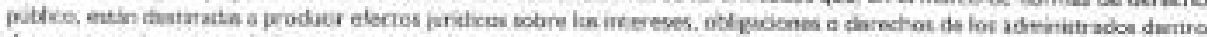

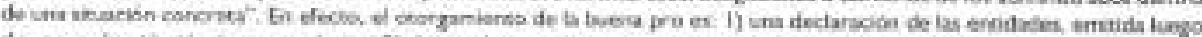

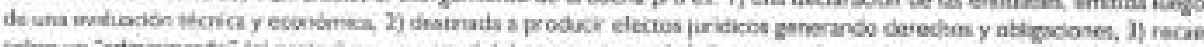

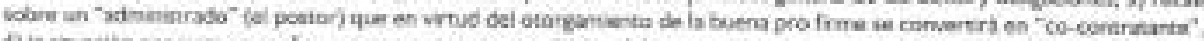

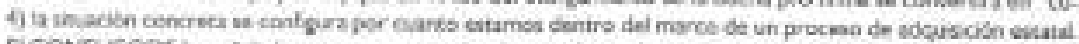

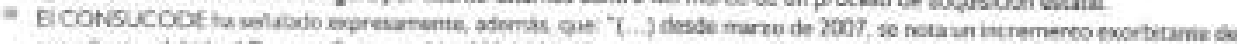

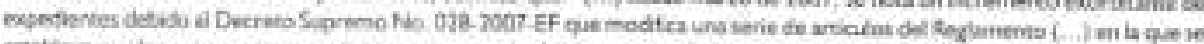

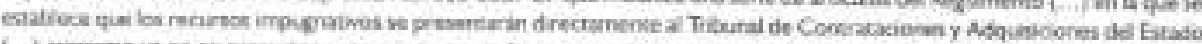

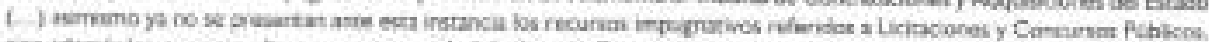

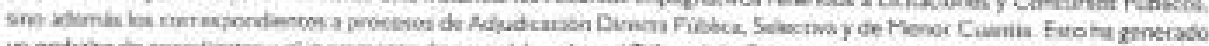

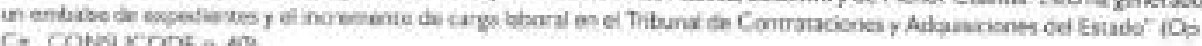

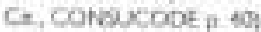


b) Cuando se veriflque la transgresián del principio de presunción de veracidad durante el proceso de selacción o para la suscripcién del contrato.

c) Clando se haya suscrito ol contrato no obstante encontrarse en tramite un recurso de apelación (les contratos son consecuencia del otorgamiento de una buena pro, pero el procoso de suscripción contractual debe necesariamente detenerse sl dicho otorgamiento, acto administrativo a traves del cual se pone de manifiesto la woluntad estatzil ${ }^{\text {, llega a ser }}$ apelado,

d) Cuando no se haya utilzado el proceso de salección correspondiente (por ajemplo, cuando en función del monto, de acuerdo a la Ley de Prosupuesto vigente, lo que debe efectuarse es una Adjudicación Directa Selectiva y se convoca a una Menor Cuantía, el cortrate que se firme como consecuencia de tal proceso, podri ser declarado nulo).

Luego se agrega un pártafo que sanciona con nulidad al proceso y al cancrato en si, cusndo se comote el gravisimo acto de contratar dircctamente bienes, servicios u obras, sin el previo proceso de selocción que corresponda

Conforme se desprende de las lineas precedertes, consideramas pasitiva la incorporación de nuevas causales da nulidad. Sin embargo, la norme deberia hacer que dicha anulaxión de oficio a que hace referencia, no sea meramerbe potestativo para la Entidad (tal como se punde intuir de la frase ${ }^{*}($...) podrat anularios de oficlo $(\ldots+)^{\prime \prime}$, sino uni cuestión que necesariamense se produzca (sugirióndose un texto del tipo "la Ensidad declarará nulos, de ofieio, les contratos que (...)", una atribución que, de no ejercerse, genere responsablichad funcional.

Asimismo, dentro de la regulación más decalada del rézimen de nuijader de corkraters con el Estado, se establece un orden de prelación de las fuentes del derecho, que deberá sar respetada por los. arbitres que tengan a su cargo evaluar la nulidad del contrato: dentro del esquerta pianteado, priman las causales del prosente Decroto Legalativa y su Plezlarnento, siguinondo las causales de nuididad provistas en las normas de dercecho püblico aglicabies.

Finalterte, en el caso del enriguecinicrto indebide (pongamos como ojemplo para esto - existo abundante casuistica al respecto - a aquel que construpe en instaladiones de ura Entidad, inmuebles que benofican a ia misma en el cumplimiento de sus fines, pero que no lo ba hecho dentre del marco

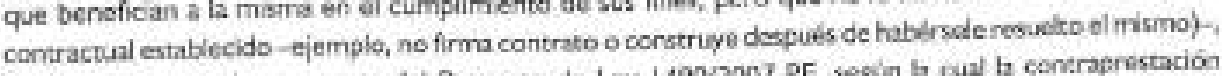
la norma descarta la propuesta del Proyecto de Ley 1490/2007-PE, según la cual b contraprestación correspondénte sera pagads en mérito de una resoludon judiclal ${ }^{2}$, mintenib́ndose el wacio existente en lo que respacta a esta problenstica.

\section{XXIV.DEL DENOMINADO "OSCE" (ORGANISMO SUPERVISOR DE LAS CONTRATACIONES DEL ESTADO)}

E) Decreto Legislativo bajo analisis cambia la denominación del actualmente lamado CONSUCODE, Asimismo, la otorga fecultades mueras, y demás particularitades, a saber:

La supervisión y fiscalización selectiva yjo aloateris de los procesos de contratación (itteral 7 ' del articulo 58).

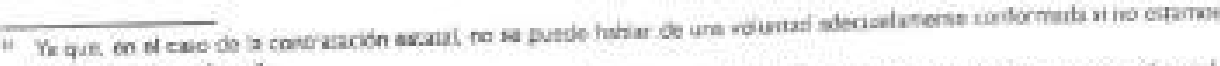
treun a un "scto firme"

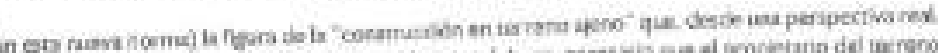

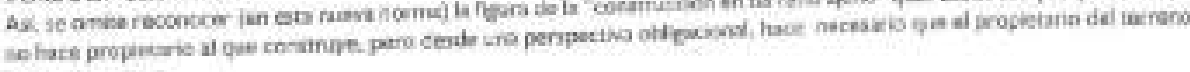


- La capacidad de suspension de las proceses de contratación, en los que como consecuenciadel ejercicio de sus funciones observe tranggresiones a la normativa en materia de contrataciones püblicas, siempre que existan indicios razonables de perjucio económico al Estado o de delito (literal "l" del articulo 58).

- La promoción de fa modalidad de "Sibasta inversa" (fireral "m")

L2 desconcentracidon de sus funciones en órganos de alcance regional a local establecido en su Reglaments de Organización y Funciocies (ROF) ruspectwo (literal " $n$ ")

- La proposición de estrategias y realización de estudios destinados al uso aficiente de los recursos públicos y reduccoón de costos (literal "n').

Tarnbién, en este mismo articulo, se esrablece la gratuidad de las consulas electuadas al OSCE por parte de las Entidados, lo cus saludamos por cianto, indudablemente, bien utillondo y er la medida en que no prolifaran pronunciamientos de cardcter contradictorio, este mecanismo cosdyovaria a una mayor oficiencia en la gestión de la contratación estatal,

\section{CONCLUSIONES Y COMENTARIOS}

Uno de los moyoces cuestionsmientos, generados mientras la estructura de la norma se escaba gestando, y que fuen expresado a diversos niveles en el necesario dobate surgido al respecto, es que dicha propuesta estaria incorporando cambios meramente cosméticos, sin mayor trascendencia. A nuestro parecer, esto no es necesariamente cierto, al encontrar los siguientas cambios, relevantes y positivos para la normativa en materia de Contratación Estatal, que pasaremos a enumerar a continunción:

1. Sustitución del "eriterio" de indagaciones aleatorias en la deţerminación del Valor Referencial. por el cricerio de las "estudios y análisis" de mercado.

2. Mayor precision terminelógica (al eliminar ha redundancia que implea la frase "contrataciones y adquisiciones del Estado" y al establecer criterios más claros qua los que presenta la normativa actual en relación a la espocialidad de la norma).

3. Rargo legal del régimen sancionatono en materia de Contratación Estatal, establockíndose una conexión directa con el fortalecimiento del Estado de Derecho.

4. Emio a la entidad de th competencia de resolver apelaciones en la mayoria de procesos de selección desarrollados, alivianando la carga procedimental del Tribunal de Contrataciones Estataies.

5. Nuevas causales do nuldad. que no se reducen a los impodimentos para contratar con el estado o al quebrantamiento del principio do presuncion de veracidad, como escuetamente seriala la noema actual.

6. Fortalocimionto de la capacidad de acoión del hoy llamado CONSUCODE, otorgándosele facultades de mipervision (por ello, precisamente, se denominari OSCE)

Preocipa, sin embargo, que no se haya desarrellado, en el proyecto, la regulación de loo lineamientos generales did rzigmen de Consultoria de Obras frecordamos que un mal estudio definitvo o espediente técrico pisede acarrear una mala obra). La misma carencia rosulta notoria para el caso de los denominados "Concirsos - Olerta"s1 (la ingente inversión púbeica que st prodice en este

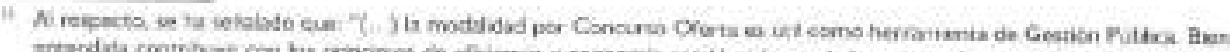

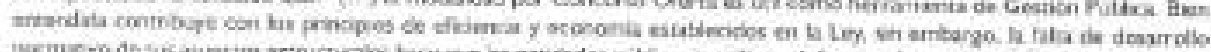

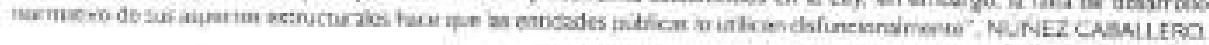


marco ameritaba un tratamionto especifice a nivel legal)." Eutos dos, consideramos, son los mass graves puntos flacos del propecto que (sin perjuicio de ha regulación tícrica que le corresponderá desarrollar al nuevo raglamento), ha debido tomar en cuenta estos dos aspectos fundamentales en el ambito de las obras públicas.

Por lo demás, consideramos que no es el tratado de Lbre Comercio, sino las necesidades pre-existentes, es decir, aquallas surgidas con anterioridad a la suscripción de este instrumento internacional, las que obligaban a una modificaciôn del régimien. Era esto último el verdadero fundamento del cambio, a menos que el Gobierno haya querido efoctuar una sistemanización, hacer una suerte de "check - list" normativo de los cambios requeridos. A margen de ello, slempre es positiva la introducción de mecaniamos que condyoven a reforzar la inatitucionalidad democrática en al pais y una buena normativa en materia de contratación estatal, contribuye enormemente a materializas tal fin. ${ }^{3}$

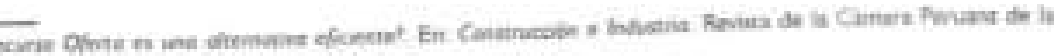
Comatrocion - CAPECO Mv XIVin, Hebrece $200 \mathrm{~A}$

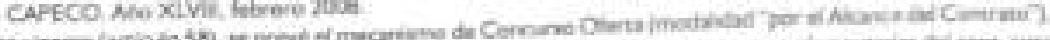

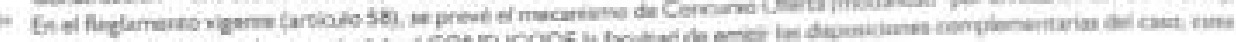

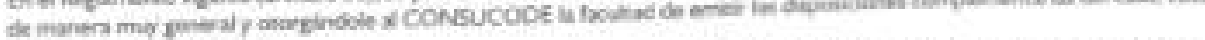
veve ne habrik probuciso

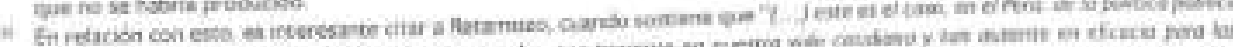

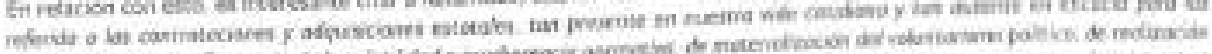

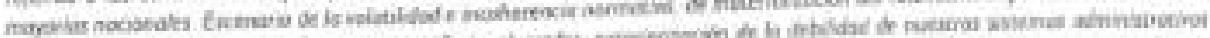

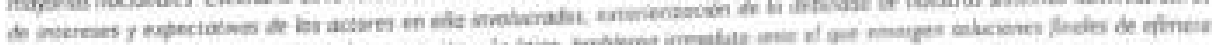

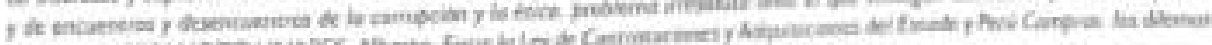

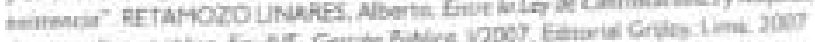

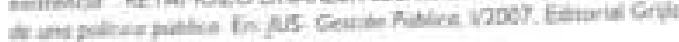

